\title{
The relationship between the psychological capital of male individuals with drug abuse and relapse tendency: A moderated mediation model
}

\author{
Xiaoqing Zeng ${ }^{1,2,3} \cdot$ Bin Wei ${ }^{1,2,3}$
}

Accepted: 16 September 2021

(c) The Author(s), under exclusive licence to Springer Science+Business Media, LLC, part of Springer Nature 2021

\begin{abstract}
This study aims to explore the mechanism of psychological capital's influence on relapse tendency of drug addicts under the COVID-19, and construct a moderated mediation model. 977 individuals with drug addiction who come from a mandatory drug rehabilitation center in China completed the Chinese versions of Psychological capital Questionnaire, the Relapse Tendency Questionnaire,the Coping Style Questionnarie and the Life History Strategy Scale.The results showed that(1) there was a significant negative correlation between psychological capital and relapse tendency;(2)positive coping style mediated the relationship between psychological capital and relapse tendency;(3) life history strategy is an important moderator between psychological capital and positive coping style.These findings help us to better understand the impact of psychological capital and positive coping style on relapse tendency.
\end{abstract}

Keywords Psychological capital $\cdot$ Positive coping style $\cdot$ Relapse tendency $\cdot$ Life history strategy

\section{Introduction}

Many studies show that the COVID-19 triggered a series of negative emotions drug users, such as depression, anxiety, irritability, fear, etc. (Martinotti et al, 2020), cause Psychological diseases such as sleep disorders and psychiatric symptoms (Chiappini et al., 2020), which have caused the exacerbation of relapse and maintenance of addiction (Ornell et al., 2020). However, these studies are mainly aimed at addicts in open communities in Western society. There are few studies on the effects of COVID-19 on addicts in closed compulsory isolation rehab.

Compulsory isolation is currently the main mode of drug rehabilitation in China. According to Chinese law, drug use is illegal. Drug users must undergo treatment and education

Xiaoqing Zeng

zxq3701@163.com

1 School of Psychology, Jiangxi Normal University, Nanchang, China

2 Jiangxi Key Laboratory of Psychology and Cognitive Science, Nanchang, China

3 Institute of Psychology, Jiangxi Normal University, Nanchang, China for 2 years in a compulsory isolation rehab. In order to ensure the effect of drug withdrawal, the compulsory isolation rehab adopt closed management. During the epidemic, in order to prevent the spread and spread of the virus, China's compulsory isolation rehab implemented stricter control measures, such as restricting visits.

Given that the participants in this study are all drug addicts who are in a compulsory isolation rehab, and they cannot be exposed to drugs during this period, we use relapse tendency as an indicator to investigate their relapse behavior after the compulsory detoxification program. Relapse tendency refers to the possibility and willingness of relapse behavior and the latter is a vital prerequisite for individuals to produce certain behaviors (Krueger et al., 2000). The higher the tendency to relapse, the higher the probability of relapse behavior. Therefore, reducing the tendency to relapse is not only an indicator to quantify the effect of drug treatment intervention, but also a major difficulty in drug treatment intervention (Zhong \& Guo, 2018).

Studies have shown that psychological capital can significantly predict substance abuse (Krasikova et al., 2015). Psychological capital refers to the individual's positive psychological development state, including four dimensions: (1) self-efficacy (undertaking and investing the necessary efforts to successfully complete the challenge); (2) optimism 
(making positive predictions about current and future success); (3) Hope (adhere to the goal and actively adjust until success); (4) Resilience (persist in adversity, transcend adversity to achieve success) (Luthans et al., 2007). Psychological capital may enable individuals to form potential cognitive agency mechanisms, including hard work, rebound from adversity, positive expectations, use of alternative solutions, etc. (Luthans et al., 2013). These mechanisms work synergistically in the field of health, guiding individuals to conduct self-directed health management, making individuals pay more attention to their own health and are willing to engage in behaviors that promote physical and mental health (Taylor et al., 2000), thereby reducing their substance use Risk (Bandura, 1999). Previous studies have also found that all the dimensions of psychological capital are closely related to substance abuse. People with higher self-efficacy have a longer retention time and a lower probability of relapse (Abdollahi et al., 2014); the higher the resilience, the lower the likelihood of substance abuse (Fadardi et al., 2010); People with high levels of hope have a stronger sense of self-efficacy and a stronger motivation for drug withdrawal(Irvlng et al., 1998); optimism and hope are decisive factors for avoiding substance abuse (Carvajal et al., 1998). However, in the context of the pandemic, as a positive state of psychological development, it is not clear whether psychological capital and the psychological mechanism that psychological capital affects the tendency to relapse will be affected by the stricter control measures adopted by the compulsory isolation rehab.

The specific effect mechanism can be explored through intermediary analysis, which has important practical significance for carrying out psychological treatment and reducing the relapse rate.

\section{The Mediating Role of Coping Style}

In cognitive therapy, drug addicts have three main dysfunctional beliefs: anticipatory beliefs (such as "I feel like a superman when I use it"); relief-oriented beliefs (such as "unless I use it, the symptoms will not disappear "); Convenience or tolerance beliefs (such as "I am a hard-working person, I am worth using it") (Onken et al., 1993). The reason for these beliefs' production may be that drug addicts tend to think quickly, and their thinking of results is either black or white (Richardson \& Hardesty, 2012).

This way of thinking may be related to the coping style of drug users, but there are few related studies. Coping style is a basic classification based on how the individual responds. It captures how people solve problems in practice (Skinner et al., 2003). Coping style can be divided into positive coping style and negative coping style. The positive coping style focuses on the problem and uses direct and rational means to solve the problem, while the negative coping style focuses on emotion and adopts avoidance, withdrawal, and wishful thinking (Ding et al., 2015).

Many studies have explored the relationship between various dimensions of psychological capital and coping style: Optimism promotes individual use of problem-centered coping (Bedi \& Brown, 2005); self-efficacy is positively correlated with the use of positive coping strategies (Devonport et al., 2006); resilience will reduce individual stress and increase effective coping behavior (Newman, 2005). These studies suggested that psychological capital is significantly related to coping style and can significantly predict coping style (Pan \& Zhou, 2009).

Coping style can also affect substance abuse. Active coping is a protective factor for relapse (Franken et al., 2001). Those who lack adaptive coping have more problems in substance use (Blevins et al., 2016). In a series of studies on alcohol abuse, researchers found that high avoidance coping is a significant predictor of alcohol abuse (Bartone et al., 2012) while adaptive coping is a protective factor for alcohol abuse (Salom et al., 2016). It can be seen that coping style are significantly related to substance abuse and can predict relapse (Pelissier \& Jones, 2006). In summary, we propose Hypothesis 1: Coping style play a mediating role in the relationship between psychological capital and relapse tendency.

\section{The Moderating Role of Life History Strategy}

Life history strategies are derived from life history theory, which believes that organisms will allocate limited resources through different strategies during their course of life (Chang et al., 2019). To facilitate research, Brumbach et al. (2009) divided life history strategies into a continuum from fast to slow. At the physiological level, the fast life history strategy means earlier physical development and sexual maturity, while the slow life history strategy points to later physical development and sexual maturity; at the psychological level, fast life history strategies are related with short-term opportunism and neglect of long-term consequences, while the slow strategies are related to long-term planning and delayed gratification (Griskevicius et al., 2013). Error management theory (Haselton \& Buss, 2000) believes that when faced with an uncertain environment, slow life history strategists tend to assume that they can control the situation, which brings them more subjective control, while fast life history strategists tend to assume that they have less control, and therefore subjectively feel less control. The sense of control over the environment affects the individual's coping style. Individuals with a high sense of control will actively and effectively control stressors (Frazier et al., 2011), while individuals with a low sense of control tend to avoid coping. It shows that there is a connection between life history strategies and coping style. 
Studies have shown that in the process of interacting with the environment, slow life history strategists will adopt more active and effective coping style (van der Linden et al., 2018), which means they are more deliberate than fast life history strategists, think about the longer term, and control emotional impulse better (Figueredo et al., 2011). Fast life history strategists tend to act impulsively, use short-term thinking to think about problems, and have a risk-taking tendency (Figueredo et al., 2006), which reflects their use of negative coping style which are emotion-centric. From this we propose hypothesis 2 : Life history strategies regulate the relationship between psychological capital and coping style.

$85.7 \%$ of drug addicts under compulsory rehabilitation in China are men (National Medical Products Administration, 2017). Therefore, strengthening research on male drug addicts under compulsory rehabilitation has broader application value. This study recruit participants on male drug addicts under compulsory rehabilitation. In conclusion, the study believes that a moderated mediation model can be constructed: to examine the mediating role of coping style between psychological capital and relapse tendency, and whether life history strategies regulate the mediation role between psychological capital and relapse tendency.

\section{Method}

\section{Participants}

A questionnaire survey was conducted on 1010 men, 977 questionnaires were returned, and the effective response rate was $96.7 \%$. The average age of the participants was $36.11 \pm 0.27$ years old. In terms of education level, 169 people have a primary school education or below, accounting for $17.3 \%$; 581 people have a junior high school education, accounting for $59.5 \%$; 188 have a high school education, accounting for $19.2 \%$; the other 39 people accounting for $4.0 \%$.

\section{Research Tools}

\section{Psychological Capital Questionnaire}

The Chinese Psychological Capital Questionnaire (Zhang et al., 2010) has 26items in 4 dimensions: self-efficacy (e.g., I believe I can analyze long-term problems and find solutions), flexibility (e.g., I can recover quickly when I encounter setbacks), hope (e.g., I am actively studying and working to realize one's ideals) and optimism (e.g., when the situation is uncertain, I always expect good results). A 7-point scale is used (where 1 is "completely nonconforming" and 7 is "completely conforming"). The average score of all items was calculated after negatively worded questions were reverse scored. In this study, the Cronbach's a coefficient of the questionnaire is 0.885 , which shows good internal consistency.

\section{Relapse Tendency Questionnaire}

The relapse tendency questionnaire has 18 items in 5 dimensions: confidence in detoxification (e.g., I believe that drug addiction can be quit through hard work), the actual influence of drugs (e.g., I hope to have the opportunity to enjoy drugs again and enjoy the addiction), objective environment (e.g., the past drug friends will come to persuade me to take drugs again during the period of taking medicine), the degree of physical and mental impairment (e.g., my health because of long-term drug use...), and the support system (my family supports and encourages me to stop taking drugs) (Zhu and Geng, 2002). The questionnaire is scored on a 6-point scale (where 0 is the lowest degree and 5 is the highest degree). In this study, the Cronbach's a coefficient of the questionnaire is 0.907 , which shows good internal consistency.

\section{Coping Style Questionnaire}

The Trait Coping Style Questionnaire (TCSQ) composed of 20 items show 2 aspects of participants' coping style: positive coping style and negative coping style (Jiang and Zhu, 1999). Negative coping style (e.g., "easy to fall into people's memories and fantasies of the event and unable to get rid of it") and positive coping style (e.g., "can quickly forget unhappiness") are each represented by 10 items, using a scale of 5 points, form 1(definitely no) to 5(definitely yes). In this study, only the positive part was selected. The higher the score, the more positive the coping style. In this study, the Cronbach's a coefficient of the questionnaire is 0.872 , which has good internal consistency.

\section{Life History Strategy Scale}

The Mini-K scale in the Arizona Life History Scale (ALHB) (Figueredo et al., 2005) was used. The scale has 20 questions (e.g., "When I was growing up, my relationship with my biological father was very close and harmonious") and scored on a 7-point scale, from -3 (strongly disagree) to 3 (strongly agree). A positive total score means a slow life history strategy, and a negative total score means a fast life history strategy. In this study, the Cronbach's a coefficient of the questionnaire is 0.893 , which shows good internal consistency. 


\section{Testing Program}

This cross-sectional study was conducted over two months, in a rehabilitation institution in China. The inclusion criteria were as follows: individuals who (a) volunteered to participate in this study, (b) were aged between 18 and 40, (c) were capable of communicating and understanding the questionnaires, and (d) had been treated in the detoxification institution for more than one month at the time of the study. A total of 1010 qualified participants were recruited. Informed consent was obtained from all participants before conducting the survey. The participants were told that they have the right to opt-out at any time. Their identities are kept anonymous and only need to be filled out according to the actual situation. The answer does not matter whether it is right or wrong. The test results are only used for scientific research and strictly confidential. The questionnaires were randomly distributed by the group during the break time, and collected on the spot after the questionnaires were filled out. A total of 977 valid questionnaires were collected.

\section{Results}

\section{Control and Inspection of Common Method Variance}

Participants measured in the form of self-report may have common method deviations. Therefore, in terms of procedural control, we try to change guidance, response sentences and the order of questions in the questionnaire design stage to balance the positive and negative questions of the questionnaire. In statistics, we used confirmatory factor analysis to test the common method deviation of all selfassessment items. The results showed that the model fit was very poor $(\mathrm{CMIN} / \mathrm{df}=10.038, \mathrm{CFI}=0.093, \mathrm{GFI}=0.244$, $\mathrm{AGFI}=0.226, \mathrm{NFI}=0.085$, RMSEA $=0.096$ ), indicating that there is no serious method deviation problem.

\section{Descriptive Statistics and Correlation Analysis}

The average, standard deviation, and correlation coefficient of each variable are shown in Table 1. Relapse tendency is significantly negatively correlated with psychological capital and positive coping style. Psychological capital is positively correlated with positive coping style and life history strategy. Positive coping style is negatively correlated with life history strategy.

\section{Moderated Mediation Model Test}

This study used the SPSS macro program process (Hayes.A.F., 2013) to test the mediating role of positive coping style between psychological capital and relapse tendency and to determine whether the first half of the path of this mediating role is regulated by life history strategy. The results are shown in Table 2. Psychological capital significantly negatively predicts relapse tendency $(b=0.23$, $p<0.001)$ and significantly positively predicts positive coping style $(b=0.41, p<0.001)$, and positive coping style has a significant negative predictive effect on relapse tendency $(b=0.20, p<0.001)$. This result shows that positive coping style mediates the influence of psychological capital on the relapse tendency of individuals with drug addiction. Thus, Hypothesis 1 is verified. In addition, the interaction between psychological capital and life history strategy has a significant predictive effect on positive coping style $(b=0.12$, $p<0.001$ ), indicating that the influence of psychological capital on positive coping style is regulated by life history strategy. Therefore, Hypothesis 2 was verified.

To better explain the mediation model with regulation, life history strategy was divided into two levels, namely slow life history strategy and fast life history strategy, which were defined as one standard deviation above and one standard deviation below respectively. A simple slopes analysis was used to investigate the role of life history strategy in the relationship between family functioning and psychological capital. The specific regulatory effect is shown in Fig. 1. Psychological capital has a significant effect on positive coping style $(b=0.5232, t=14.4453, p<0.001,95 \%$ Bootstrap $\mathrm{CI}=[0.4521,0.5943])$ when drug addicts under compulsory rehabilitation adopt fast life history strategies, while psychological capital has a weaker effect on positive coping style $(b=0.2878, t=7.5859, p>0.001,95 \%$ Bootstrap $\mathrm{CI}=[0.2133,0.3623])$. Therefore, psychological capital has a greater effect on the positive coping style of drug addicts under compulsory rehabilitation who adopt fast life history strategies than on individuals with drug addiction who adopt slow life history strategies.
Table 1 Measures, standard deviations, and intercorrelations of the study measures

\begin{tabular}{lrcllll}
\hline & M & SD & 1 & 2 & 3 & 4 \\
\hline 1. Relapse tendency & 26.61 & 14.08 & 1 & & & \\
2. Psychological capital & 4.45 & 0.711 & $-0.288^{* *}$ & 1 & & \\
3. Positive coping style & 40.54 & 9.63 & $-0.269^{* *}$ & $0.331^{* *}$ & 1 & \\
4. Life history strategy & 4.09 & 18.55 & -0.008 & $0.200^{* *}$ & $-0.321^{* *}$ & 1 \\
\hline
\end{tabular}

$N=977,{ }^{*} P<0.05,{ }^{* *} P<0.01,{ }^{* * *} P<0.001$, the same below. 
Table 2 Regression Analysis of the mediating role of life history strategies in psychological capital and relapse tendency

\begin{tabular}{|c|c|c|c|c|c|c|c|c|}
\hline \multicolumn{2}{|l|}{ Regression equation } & \multicolumn{3}{|c|}{ Overall Model Fit } & \multicolumn{4}{|c|}{$\begin{array}{l}\text { Regression Coefficient Signifi- } \\
\text { cance }\end{array}$} \\
\hline Outcome & Predictor & $R$ & $R^{2}$ & $F$ & $\beta$ & LLCI & ULCI & $t$ \\
\hline \multirow[t]{5}{*}{ Positive coping style } & Age & 0.53 & 0.28 & $77.26 * * *$ & 0.00 & 0.00 & 0.01 & 0.86 \\
\hline & Residence & & & & 0.04 & -0.07 & 0.15 & 0.71 \\
\hline & Psychological capital & & & & 0.41 & 0.35 & 0.46 & $14.60^{* * *}$ \\
\hline & Life history strategy & & & & -0.38 & -0.44 & -0.33 & $-13.47^{* * *}$ \\
\hline & $\begin{array}{l}\text { Psychological } \\
\text { capital } \times \text { life history } \\
\text { strategy }\end{array}$ & & & & -0.12 & -0.17 & -0.07 & $-4.79^{* * *}$ \\
\hline \multirow[t]{4}{*}{ Relapse tendency } & Age & 0.35 & 0.12 & $33.49 * * *$ & 0.01 & 0.00 & 0.01 & 1.38 \\
\hline & Residence & & & & 0.10 & -0.03 & 0.22 & 1.51 \\
\hline & Psychological capital & & & & -0.23 & -0.29 & -0.16 & $-7.05^{* * *}$ \\
\hline & Positive coping style & & & & -0.20 & -0.26 & -0.13 & $-6.17^{* * *}$ \\
\hline
\end{tabular}

All variables in the model were brought into the regression equation after standardized treatment, the same below. Residence: $1=$ rural, 2 = city.

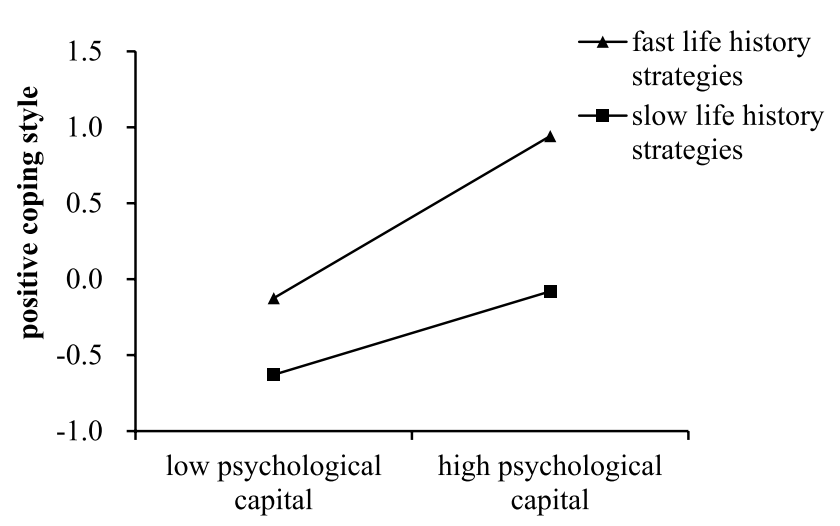

Fig. 1 Diagram of the moderating effect of life history strategy on the relationship between Psychological capital and positive coping style

In conclusion, this study constructed a moderated mediation model (as shown in Fig. 2) and explored the influence of psychological capital to relapse tendency as well as its internal mechanism.

\section{Discussion}

\section{The Mediating Role of Positive Coping Style}

This study found that the psychological capital of the addicts was at a medium level, which was roughly equivalent to the research results of Xu Rong (2020). The psychological capital of the community abstinent people abroad also fluctuated at a medium level (Mohammadi et al., 2018). This indicates that the lockdown did not reduce the psychological capital of the drug addicts under compulsory rehabilitation. The reason may be that those who are in rehab are themselves less exposed to the impact of the epidemic. Moreover, the compulsory isolation rehab is closed management at the very beginning. At this time, only family visits are temporarily cut off, which has limited influence on the psychological capital of the addicts.

In the Chinese cultural context, suppressing emotions is considered to be a universally acceptable cultural norm
Fig. 2 The model of the effect of psychological capital on relapse tendency

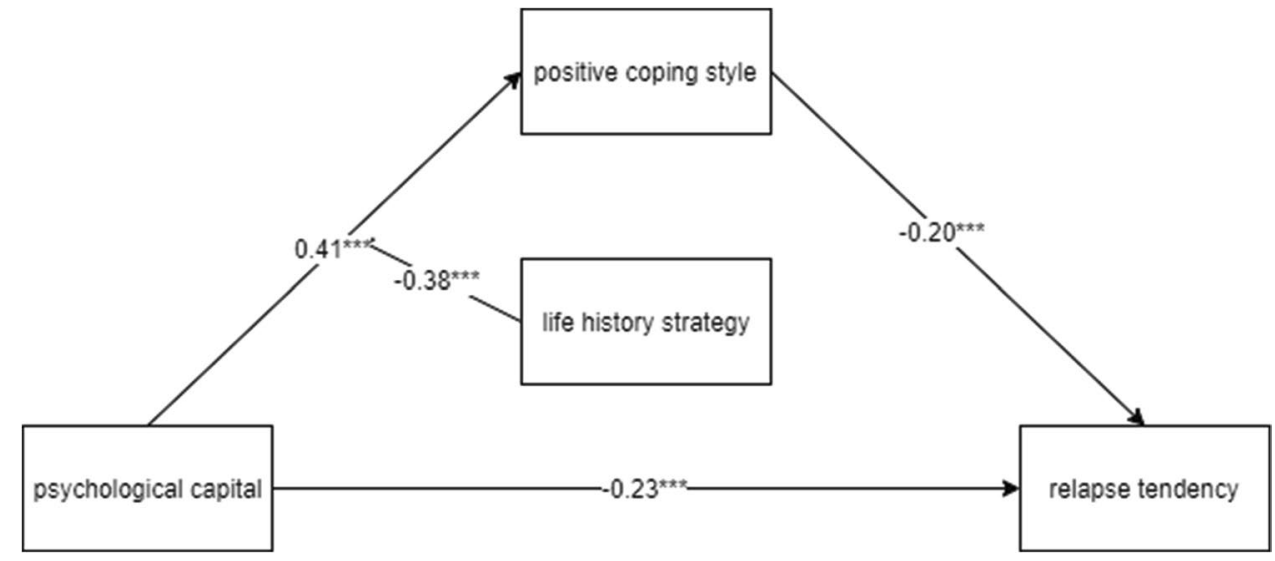


(Chang \& Edwards, 2015), rather than proactively solving problems. Therefore, individuals with low psychological capital are more likely to adopt emotion-centered coping style.

This study also found that psychological capital is significantly positively correlated with positive coping style, which is consistent with previous studies (Khan et al., 2011). Positive coping style serve as a bridge connecting psychological capital and relapse tendency, showing a partial mediating effect. drug addicts under compulsory rehabilitation are facing greater pressure than in previous life situations. According to the general stress theory (Agnew, 2001), the sources of stress can be divided into three types: the disappearance of positive stimuli, the emergence of negative stimuli, and the failure to achieve the desired goal. For our addicts, these three refer to the absence of drugs, the emergence of isolation, and the inability to use drugs (Chen et al., 2020). Individuals with high psychological capital have a good mentality to deal with these pressures, while individuals with lower psychological capital may fall into more negative emotions because of the existence of these pressures. Coupled with the existence of long-term social stigma, they are generally lack of sufficient social resources to cope with these pressures, which force them to adopt negative coping style, which increases the probability of relapse.

In addition, the education level of the drug addicts in this study is generally low, with a high school degree or above accounting for only $3.3 \% ; 34.7 \%$ of the people are even unemployed. That means they are in a low social status, prone to relative deprivation (Compared with the reference group, the individual's subjective perception of their own disadvantage) (Walker \& Smith, 2002). The relative deprivation will increase the individual's avoidance coping behavior. Individuals in a relatively disadvantaged position may experience stronger stress and depression, increase the risk of participating in dangerous avoidance behaviors such as smoking, alcoholism, and drug abuse (Eibner \& Evans, 2005). For individuals with high psychological capital, they have a stronger ability to cope with anxiety and depression (Liu et al., 2014), as well as sufficient self-efficacy and resilience to cope actively. Individuals with low psychological capital are easily involved in a sense of relative deprivation, tend to use more avoidance coping style, which means their probability of relapse is also higher.

\section{The Moderating Effect of Life History Strategy}

This study found that life history strategies regulate the first half of the path of psychological capital affecting relapse propensity through positive coping style. Specifically, compared with drug addicts under compulsory rehabilitation with slow life history strategies, the psychological capital of drug addicts with fast life history strategies predict positive coping style more effectively, which is inconsistent with the results of previous studies (van der Linden et al., 2018).

Life history theory believes that slow life history strategies are superior to fast life history strategies, because slow life history strategies are more in line with social norms, which means those who use slow life history strategies are more likely to achieve higher social status by obey social norms, have more influence, more in line with the requirements of society (Figueredo et al., 2006; Sherman et al., 2013). However, the average age of the participants in this study was 36.11 years old, which means they were born and raised in the period when China was undergoing reform and opening up and the living environment was constantly changing. In this era of rapid economic development and ever-changing environment, Chinese not only have abundant growth resources, but also facing the changeable living environment. The fast life history strategy not only an adaptation strategy for a resource-rich environment (Lu et al., 2017), and also more advantageous in unpredictable environments (Brumbach et al., 2009). For fast life history strategists who adapt to the environment, they have a stronger sense of control (Sherman et al., 2013) and are more focused on the present, so they are more inclined to choose the way of active control-a adaptive way in either stable or rapidly changing environment (Tops, 2014)-to respond to stressful events, that is, to adopt a positive response method.

Secondly, under the overall stable development of human society, the slow life history strategy has high adaptability. The coral reef model believes that different life history strategies are suitable for different microenvironments (Figueredo et al., 2011). The participants in this study are currently in this micro-environment in the compulsory isolation rehab. In order to block the spread of COVID-19 and ensure the withdrawal effect, the compulsory isolation rehab is isolated from the external environment and has strict management; In terms of the social environment, differently from normal people, they are facing with problems such as stigma, poverty, and employment difficulties. Therefore, the microenvironment the drug addicts located has its own characteristics, and accordingly, the life history strategy also reflects the different adaptability of the more usual research.

Thirdly, the fast life history strategy can be represented by several main behavior tendencies, such as risk-taking preference, instant gratification, and lower prosocial tendencies (Wu et al., 2020). The preference for risk makes the individual's assessment of risk more positive, treating risk as a challenge rather than a threat, so that he can take more active actions instead of avoiding the problem; the preference for instant gratification makes the individual more focused on the solution of the current problem; Weak pro-social behavior tendencies mean more independence, which is an adaptive feature in a more mobile environment (Oishi, 2010). For groups with adaptive fast life history 
strategies, these behavior tendencies are helpful to promote its positive response style. The theory of directional adjustment (Higgins, 1998) believes that one of the basic principles of human motivation is the principle of hedonism, which is to avoid suffering and pursue happiness. There are two different operational modes of the hedonic principle, namely promotion focus and prevention focus. Individuals who use promotion focus are more concerned about obtaining positive results and how to approach the goal; individuals who use prevention focus are more concerned about the elimination of negative results, that is, what to avoid. For individuals who adopt the fast life history strategy, they are more daring to take risks, be good at seizing opportunities and using existing resources, which makes it easier for them to keep promotion focus; for individuals with use slow life history strategy, they have a strong tendency to avoid risks (Figueredo et al., 2006), fear the loss of existing resources, and are more likely to adopt preventive focus, which makes them adopt emotioncentric or avoidant response measures. The former means a stronger problem-solving ability, which is more suitable for current China with the rapid economic development and market changes.

In fact, after controlling social expectations, the personality defects of the slow-life history strategists have also been revealed. They are kind and reliable, hardworking and considerate, but clumsy, inactive, and lack social skills; on the contrary, the fast life history strategists exhibit a series of benign qualities that have been overlooked in previous studies, such as more self-confidence, stronger desire to control (Sherman et al., 2013), which means they are more likely to respond positively to stress.

The main sources of pressure faced by the participants in this study are seeking job, supporting the elderly, raising children, etc., that is, mainly economic pressure. To solve the above pressure, they need to reintegrate into society and participate in employment, but the stigma and discrimination has imposed both psychological resistance and practical resistance on this. For fast life history strategists, they are easier to take action due to their risk tendency, while slow life history strategists who are more concerned about reputation (Wu et al., 2017) tend to use emotional coping or avoiding coping because exposed to social insights and the possibility of rejection means a greater psychological burden for them, makes their own avoidance tendencies intensified. In fact, when faced with uncontrollable stressors, individuals will produce negative emotions such as depression and anxiety (Folkman, 2008); especially for drug users, in terms of brain mechanisms, their stress circuit and the assumed reward circuit Is activated (Sinha, 2001); at this time emotional coping is more adaptive (Austenfeld \& Stanton, 2004). As a source of stress, stigma from society is difficult for individuals to control. As a result, individuals are more likely to use drugs to ease their emotions and reduce stress (Khantzian, 1987).

\section{Research Significance and Shortcomings}

This research has some important implications. We theoretically clarified the psychological mechanism that affects the tendency to relapse, and provide a theoretical basis for reducing the tendency to relapse. Firstly, psychological capital is highly correlated with the tendency to relapse. For this reason, we must pay attention to the psychological capital of drug addicts under compulsory rehabilitation, give them more care, help them maintain contact with their families, and improve their psychological capital. Secondly, positive coping style play a mediating role between psychological capital and relapse tendency. It means that in rehabilitation education, addicted individuals should be taught a problem-solving-oriented positive coping style, and help them build confidence in coping with problems. Thirdly, life history strategies reflect different effects on the drug addicts from the general environment which enlightens us that following research should abandon the comparative views on the advantages of fast and slow life history strategies and focus on the adaptability of different life history strategies in different environments.

This study still has the following shortcomings: Firstly, the study adopts a cross-sectional design, which cannot ascertain the causal relationship between variables; the self-report method is used to collect data which could cause a certain self-report bias. Follow-up research were considered to use the experimental method. Secondly, the research object of this article is drug addicts under compulsory rehabilitation. The evaluation methods and treatment procedures used to help-seekers under different cultural backgrounds are different, thus limiting the research object to a certain area will make the results more targeted (Bhui et al., 2002). Therefore, It should be cautious when applying the results of this study to voluntary drug addicts and other cultures. Thirdly, there are gender differences in drug abuse. For example, Pelissier and Jones (2006) found that women are more aware of drug use problems, but rely more on negative coping style such as seeking support and avoidance, so the results of this study may not be suitable for female addicts.

\section{Conclusion}

Psychological capital negatively predicts the tendency to relapse; positive coping style play a part of the mediating role between psychological capital and relapse tendency; life history strategies regulate the relationship between psychological capital and positive coping style. There are no one better than the other for fast and slow life history strategies. Their advantages should be considered in different environments. 
Author's Contribution Xiaoqing Zeng: Conceptualization, Methodology, Data Collection, Visualization. Writing — original draft, reviewing, and editing; Bin Wei: Software, Writing_original draft, reviewing, editing, and submission. All authors have read and agreed to the published version of the manuscript.

Funding This research was supported by grants from the National Social Science Foundation of China (19BGL230), and from the "13th Five-Year Plan" Project of Educational Science in Jiangxi Province (20YB19)

Data Availability All data generated or analysed during this study are included in the supplementary information files.

Code Availability Not applicable.

\section{Declarations}

Conflicts of Interest The authors declare no conflict of interest.

Ethics Approval The across-sectional study was carried out in accordance with the recommendations of the Morals \& Ethics Committee of the School of Psychology, Jiangxi Normal University (Nanchang, China).

Consent to Participate Since we are a questionnaire experiment, informed consent is required to be signed before answering the questionnaire, and all the participants have signed informed consent.

The informed consent forms are available in the below. Since our questionnaires are all in Chinese, I converted them into English for ease of understanding. If you have any questions, please contact us at any time.

Informed Consent Hello! We are a research team from the School of Psychology of Jiangxi normal University. Thank you very much for taking the time to complete this questionnaire during your busy schedule. This study has been approved by the ethics committee of the school of psychology. This is an academic questionnaire designed to understand the relationship between the State of mind and living conditions of the person with substance use disorder. Your comments will be an important source of data for this study, and we would appreciate your assistance. In addition, You can ask us for information about this questionnaire at any time.

This formal questionnaire is divided into four parts. Please select the most appropriate option according to your real situation and thoughts. It takes about $30 \mathrm{~min}$ to complete the questionnaire.

This questionnaire will be anonymous and will not have any impact on your current living. All information collected during the survey will be strictly confidential and will be kept by the investigator. Thank you again for your selfless help, we wish you good health, get well soon! This survey is entirely voluntary. If you are aware of and agree to the above statement, please sign your approval on the horizontal line and fill in the date of the day:

\section{References}

Abdollahi, Z., Taghizadeh, F., Hamzehgardeshi, Z., \& Bahramzad, O. (2014). Relationship between addiction relapse and self-efficacy rates in injection drug users referred to Maintenance Therapy Center of Sari, 1391. Global Journal of Health Science, 6(3), 138-144. https://doi.org/10.5539/gjhs.v6n3p138
Agnew, R. (2001). Building on the foundation of general srain theory:specifying the types of strain most likely o lead to crime and delinquency. Journal of Research in Crime and Delinquency, 38, 319-361. https://doi.org/10.1080/07418829200091521

Austenfeld, J. L., \& Stanton, A. L. (2004). Coping through emotional approach: A new look at emotion, coping, and health-related outcomes. Journal of Personality, 72(6), 1335-1364. https://doi.org/ 10.1111/j.1467-6494.2004.00299.x

Bandura, A. (1999). Special Section An Agentic Perspective. Psychological Science, 10(3), 214-217.

Bartone, P. T., Hystad, S. W., Eid, C. J., \& Brevik, J. I. (2012). Psychological hardiness and coping style as risk/resilience factors for alcohol abuse. Military Medicine, 177(5), 517-524. https://doi. org/10.7205/MILMED-D-11-00200.

Bedi, G., \& Brown, S. L. (2005). Optimism, coping style and emotional well-being in cardiac patients. British Journal of Health Psychology, 10(1), 57-70. https://doi.org/10.1348/135910704X15266

Bhui, K., Chandran, M., \& Sathyamoorthy, G. (2002). Mental health assessment and south Asian men. International Review of Psychiatry, 14(1), 52-59. https://doi.org/10.1080/09540260120114069

Blevins, C. E., Abrantes, A. M., \& Stephens, R. S. (2016). Motivational pathways from antecedents of alcohol use to consequences: A structural model of using alcohol to cope with negative affect. American Journal of Drug and Alcohol Abuse, 42(4), 395-403. https://doi.org/10.3109/00952990.2016.1141915

Brumbach, B. H., Figueredo, A. J., \& Ellis, B. J. (2009). Effects of harsh and unpredictable environments in adolescence on development of life history strategies: A Longitudinal Test of an Evolutionary Model. Human Nature, 20(1), 25-51. https://doi.org/10. 1007/s12110-009-9059-3

Carvajal, S. C., Clair, S. D., Nash, S. G., \& Evans, R. I. (1998). Relating optimism, hope, and self-esteem to social influences in deterring substance use in adolescents. Journal of Social and Clinical Psychology, 17(4), 443-465. https://doi.org/10.1521/jscp.1998. 17.4.443

Chang, L., Lu, H. J., Lansford, J. E., Skinner, A. T., Bornstein, M. H., Steinberg, L., Dodge, K. A., Chen, B. B., Tian, Q., Bacchini, D., Deater-Deckard, K., Pastorelli, C., Alampay, L. P., Sorbring, E., Al-Hassan, S. M., Oburu, P., Malone, P. S., Di Giunta, L., Uribe Tirado, L. M., \& Tapanya, S. (2019). Environmental harshness and unpredictability, life history, and social and academic behavior of adolescents in nine countries. Developmental Psychology, 55(4), 890-903. https://doi.org/10.1037/dev0000655

Chang, Y., \& Edwards, J. K. (2015). Examining the Relationships Among Self-Efficacy, Coping, and Job Satisfaction Using Social Career Cognitive Theory: An SEM Analysis. Journal of Career Assessment, 23(1), 35-47. https://doi.org/10.1177/1069072714 523083

Chen, M., Zeng, X., \& Chen, Y. (2020). Self-concept and abstinence motivation in male drug addicts: Coping style as a mediator. Social Behavior and Personality, 48(7). https://doi.org/10.2224/ sbp.9334

Chiappini, S., Guirguis, A., John, A., Corkery, J. M., \& Schifano, F. (2020). COVID-19: The Hidden Impact on Mental Health and Drug Addiction. Frontiers in Psychiatry, 11(July), 10-13. https:// doi.org/10.3389/fpsyt.2020.00767

Devonport, T. J., Lane, A. M., City, I., Campus, W., \& Road, G. (2006). Relationship between self-efficacy, coping and student retention. Social Behavior and Personality 34(2), 127-138. https:// doi.org/10.2224/sbp.2006.34.2.127

Ding, Y., Yang, Y., Yang, X., Zhang, T., Qiu, X., He, X., Wang, W., Wang, L., \& Sui, H. (2015). The mediating role of coping style in the relationship between psychological capital and burnout among Chinese nurses. PLoS ONE, 10(4), 1-14. https://doi.org/10.1371/ journal.pone. 0122128 
Eibner, C., \& Evans, W. N. (2005). Relative deprivation, poor health habits, and mortality. Journal of Human Resources, 40(3), 591620. https://doi.org/10.3368/jhr.xl.3.591

Fadardi, J. S., Azad, H., \& Nemati, A. (2010). The relationship between resilience, motivational structure, and substance use. Procedia Social and Behavioral Sciences, 5, 1956-1960. https://doi.org/10. 1016/j.sbspro.2010.07.395

Figueredo, A. J., Andrzejczak, D. J., Jones, D. N., Smith-Castro, V., \& Montero, E. (2011). Reproductive strategy and ethnic conflict: Slow life history as a protective factor against negative ethnocentrism in two contemporary societies. Journal of Social, Evolutionary, and Cultural Psychology, 5(1), 14-31. https://doi.org/ 10.1037/h0099277

Figueredo, A. J., Vásquez, G., Brumbach, B. H., Schneider, S. M. R., Sefcek, J. A., Tal, I. R., Hill, D., Wenner, C. J., \& Jacobs, W. J. (2006). Consilience and Life History Theory: From genes to brain to reproductive strategy. Developmental Review, 26(2), 243-275. https://doi.org/10.1016/j.dr.2006.02.002

Figueredo, A. J., Vasquez, G., Brumbach, B. H., Sefcek, J. A., Kirsner, B. R., \& Jacobs, W. J. (2005). The K -factor: Individual Differences in Life History Strategy. Personality and Individual Differences, 39, 1349-1360. https://doi.org/10.1016/j.paid.2005.06.009

Folkman, S. (2008). An The case for positive emotions in the stress process. Anxiety, Stress, \& Coping: An International Journal, 21(1), 3-14. https://doi.org/10.1080/10615800701740457

Franken, I. H. A., Hendriks, V. M., Haffmans, P. M. J., \& Van Der Meer, C. W. (2001). Coping style of substance-abuse patients: Effects of anxiety and mood disorders on coping change. Journal of Clinical Psychology, 57(3), 299-306. https://doi.org/10.1002/ jclp. 1013

Frazier, P., Keenan, N., Anders, S., Perera, S., Shallcross, S., \& Hintz, S. (2011). Perceived Past, Present, and Future Control and Adjustment to Stressful Life Events. Journal of Personality and Social Psychology, 100(4), 749-765. https://doi.org/10.1037/a0022405

Griskevicius, V., Ackerman, J. M., Cantú, S. M., Delton, A. W., Robertson, T. E., Simpson, J. A., Thompson, M. E., \& Tybur, J. M. (2013). When the Economy Falters, Do People Spend or Save? Responses to Resource Scarcity Depend on Childhood Environments. Psychological Science, 24(2), 197-205. https://doi.org/10. 1177/0956797612451471

Haselton, M. G., \& Buss, D. M. (2000). Error management theory: A new perspective on biases in cross-sex mind reading. Journal of Personality and Social Psychology, 78(1), 81-91. https://doi.org/ 10.1037/0022-3514.78.1.81

Hayes, A. F. (2013). Introduction to mediation,moderation, and conditional process analisis:A regression-based approach. Journal of Educational Measurement, 51, 335-337.

Higgins, E. T. (1998). Promotion and Prevention: Regulatory Focus as A Motivational Principle. Advances in Experimental Social Psychology, 30(C), 1-46. https://doi.org/10.1016/S0065-2601(08) 60381-0

Irvlng, L. M., Seidner, A. L., Burling, T. A., Pagliarini, R., \& RobbinsSisco, D. (1998). Hope and recovery from substance dependence in homeless veterans. Journal of Social and Clinical Psychology, 17(4), 389-406. https://doi.org/10.1521/jscp.1998.17.4.389

Jiang, Q., \& Zhu, Y. (1999). Further explorations for a coping style questionnaire. Department of Medical Psychology, 8(3), 167-169.

Khan, A., Siraj, S., \& Li, L. P. (2011). Role of Positive Psychological Strengths and Big five Personality Traits in Coping Mechanism of University Students. Society and Culture LPEDR, 20, 210-215.

Khantzian, E. J. (1987). The Cocaine Crisis. The Cocaine Crisis, 65-74. https://doi.org/10.1007/978-1-4613-1837-8

Krasikova, D. V., Lester, P. B., \& Harms, P. D. (2015). Effects of Psychological Capital on Mental Health and Substance Abuse. Journal of Leadership and Organizational Studies, 22(3), 280291. https://doi.org/10.1177/1548051815585853
Krueger, N. F. J., Reilly, M. D., \& Carsrud, A. L. (2000). Competing Models of Entrepreneurial Intentions. Journal of Business Venturing, 15(98), 411-432.

Liu L., Wen F., Xu X \& Wang L. (2014). Effective Resources for Improving Mental Health among Chinese Underground Coal Miners: Perceived Organizational Support and Psychological Capital. Journal of Occupational Health Psychology, 1-33. https://doi.org/10.1037/1076-8998.8.3.c2

Lu, H., Wong, K., \& Chang, L., (2017). The association between life history strategy and mate preference in men. Personality and Individual Differences, 116(October), 157-163. https://doi.org/ 10.1016/j.paid.2017.04.047

Luthans, F., Avolio, B. J., Avey, J. B., \& Norman, S. M. (2007). DigitalCommons@ University of Nebraska - Lincoln Positive Psychological Capital : Measurement and Relationship with Performance and Satisfaction Positive Psychological Capital : Measurement and Relationship with Performance and Satisfaction. Personnel Psychology, 60, 541-572.

Luthans, F., Youssef, C. M., Sweetman, D. S., \& Harms, P. D. (2013). Meeting the leadership challenge of employee wellbeing through relationship Psycap and health PsyCap. Journal of Leadership and Organizational Studies, 20(1), 118-133. https://doi.org/10.1177/1548051812465893

Martinotti, G., Alessi, M. C., Di Natale, C., Sociali, A., Ceci, F., Lucidi, L., Picutti, E., Di Carlo, F., Corbo, M., Vellante, F., Fiori, F., Tourjansky, G., Catalano, G., Carenti, M. L., Incerti, C. C., Bartoletti, L., Barlati, S., Romeo, V. M., Verrastro, V., ... di Giannantonio, M. (2020). Psychopathological Burden and Quality of Life in Substance Users During the COVID-19 Lockdown Period in Italy. Frontiers in Psychiatry, 11(September), 1-8. https://doi.org/10.3389/fpsyt.2020.572245

Mohammadi, M., Mehriar, A., \& Souri, A. (2018). The Relationship between Family-Social Factors and Substance Use: The Mediating Role of Individuals' Temperament, Character, Psychological Capital, and Beliefs. Research on Addiction, 12(4600746), 273-296.

Newman, R. (2005). APA's resilience initiative. Professional Psychology: Research and Practice, 36(3), 227-229. https://doi.org/10. 1037/0735-7028.36.3.227

National Medical Products Administration. (2017). National Drug Abuse Monitoring Annual Report (2016). https://www.nmpa.gov. cn/xxgk/fgwj/gzwj/gzwjyp/20170811104001233.html

Oishi, S. (2010). The psychology of residential mobility: Implications for the self, social relationships, and Well-Being. Perspectives on Psychological Science, 5(1), 5-21. https://doi.org/10.1177/17456 91609356781

Onken, L. S., Blaine, J. D., \& Boren, J. J. (1993). Behavioral treatments for drug abuse and dependence: Progress, potential, and promise. NIDA Research Monograph Series, 137, 1-4.

Ornell, F., Moura, H. F., Scherer, J. N., Pechansky, F., Kessler, F. H. P., \& von Diemen, L. (2020). The COVID-19 pandemic and its impact on substance use: Implications for prevention and treatment. Psychiatry Research, 289(May), 113096. https://doi.org/10. 1016/j.psychres.2020.113096

Pan, Q., \& Zhou, Z. (2009). Psychological capital, coping style and psychological health: An empirical study from college students. 2009 1st International Conference on Information Science and Engineering, ICISE 2009, 3391-3394. https://doi.org/10.1109/ ICISE.2009.860

Pelissier, B., \& Jones, N. (2006). Differences in motivation, coping style, and self-efficacy among incarcerated male and female drug users. Journal of Substance Abuse Treatment, 30(2), 113-120. https://doi.org/10.1016/j.jsat.2005.10.006

Richardson, G. B., \& Hardesty, P. (2012). Immediate survival focus: Synthesizing life history theory and dual process models to explain substance use. Evolutionary Psychology, 10(4), 731-749. https://doi.org/10.1177/147470491201000408 
Salom, C. L., Kelly, A. B., Alati, R., Williams, G. M., Patton, G. C., \& Williams, J. W. (2016). Individual, school-related and family characteristics distinguish co-occurrence of drinking and depressive symptoms in very young adolescents. Drug and Alcohol Review, 35(4), 387-396. https://doi.org/10.1111/dar.12303

Sherman, R. A., Figueredo, A. J., \& Funder, D. C. (2013). The behavioral correlates of overall and distinctive life history strategy. Journal of Personality and Social Psychology, 105(5), 873-888. https://doi.org/10.1037/a0033772

Sinha, R. (2001). How does stress increase risk of drug abuse and relapse ? Psychopharmacology (berl), 158, 343-359. https://doi. org/10.1007/s002130100917

Skinner, E. A., Edge, K., Altman, J., \& Sherwood, H. (2003). Searching for the Structure of Coping: A Review and Critique of Category Systems for Classifying Ways of Coping. Psychological Bulletin, 129(2), 216-269. https://doi.org/10.1037/0033-2909.129.2.216

Walker, I., \& Smith, H. J. (Eds.) (2002). Relative deprivation: Specification, development, and integration. Cambridge University Press.

Taylor, S. E., Kemeny, M. E., Reed, G. M., Bower, J. E., \& Gruenewald, T. L. (2000). Psychological resources, positive illusions, and health. American Psychologist, 55(1), 99-109. https://doi.org/ 10.1037/0003-066X.55.1.99

Tops, M. (2014). Slow Life History Strategies and Slow Updating of Internal Models: The Examples of Conscientiousness and Obsessive-Compulsive Disorder. Psychological Inquiry, 25(3-4), 376-384. https://doi.org/10.1080/1047840X.2014.916194

van der Linden, D., Dunkel, C. S., Tops, M., Hengartner, M. P., \& Petrou, P. (2018). Life history strategy and stress: An effect of stressful life events, coping strategies, or both? Personality and
Individual Differences, 135(March), 277-285. https://doi.org/10. 1016/j.paid.2018.07.024

Wu, J., Balliet, D., Tybur, J. M., Arai, S., Van Lange, P. A. M., \& Yamagishi, T. (2017). Life history strategy and human cooperation in economic games. Evolution and Human Behavior, 38(4), 496-505. https://doi.org/10.1016/j.evolhumbehav.2017.03.002

Wu, J., Guo, Z., Gao, X., \& Kou, Y. (2020). The relations between early-life stress and risk, time, and prosocial preferences in adulthood: A meta-analytic review. Evolution and Human Behavior. https://doi.org/10.1016/j.evolhumbehav.2020.09.001

$\mathrm{Xu}, \mathrm{R} .(2020)$. The relationship between positive psychological capital and relapse tendency in male drug abstainers:the intermediate effect of motivation to abstain from drugs. Chin J Drug Depend.,29(5),383-386. https://doi.org/10.13936/j.cnki.cjdd1 992.2020.05.011

Zhang, K., Zhang, S., \& Dong, Y. (2010). Positive Psychological Capital: Measurement and Relationship with Mental Health. Stud. Psychol. Behav., 8, 58-64.

Zhong, W., \& Guo, Y. (2018). Effect of Resilience on Drug Relapse Risk: The Mediating Roles of Perceived Stress and Depression. Chinese Journal of Clinical Psychology, 26 (06), 10961099+1103. https://doi.org/10.16128/j.cnki.1005-3611.2018.06. 010

Zhu, W., \& Geng, W. (2002). The risk factors of heroin-addicts' relapse. Chin. J. Behav. Med. Sci., 11, 20-22.

Publisher's Note Springer Nature remains neutral with regard to jurisdictional claims in published maps and institutional affiliations. 